\title{
ИЗВЛЕЧЕНИЕ РЕДКОЗЕМЕЛЬНЫХ МЕТАЛЛОВ ИЗ ВТОРИЧНОГО СЫРЬЯ
}

\author{
Г.А. Колобов ${ }^{1}$, В.В. Павлов ${ }^{2}$, К.А. Печерица ${ }^{3}$, Ю.В. Мосейко ${ }^{1}$, \\ Н.В. Личконенко ${ }^{1}$, А.Д. Прохорова ${ }^{4}$

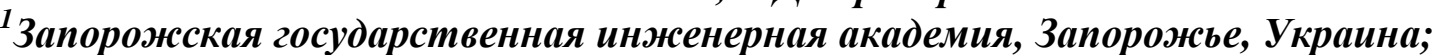 \\ ${ }^{2}$ ПАО «Институт титана», Запорожсье, Украина; \\ ${ }^{3}$ ООО «Титан Трейд», Запорожье, Украина; \\ ${ }^{4}$ Карагандинский государственный технический университет, Караганда, Казахстан \\ E-mail: kolobovgerman2019@gmail.com; тел. +38(068)908-68-22
}

Дан обзор новых публикаций, посвященных технологиям извлечения редкоземельных металлов (РЗМ) из различных видов вторичного сырья: скрапа постоянных магнитов, изготовленных из сплава $\mathrm{Nd}_{2} \mathrm{Fe}_{14} \mathrm{~B}$, и никель-металлгидридных аккумуляторных батарей; отработанных катализаторов; скрапа электроники; отходов люминофоров и скрапа флуоресцентных ламп.

\section{ВВЕДЕНИЕ}

Составной частью группы редких металлов является подгруппа редкоземельных металлов (РЗМ), которая состоит из 17 элементов III группы периодической системы: скандия, иттрия, лантана и семейства из 14 лантаноидов - от церия (порядковый номер 58) до лютеция (71).

Последние десятилетия демонстрируют значительный рост производства и потребления редкоземельной продукции. В настоящее время более 80\% всего объема производимых РЗМ приходится на три области использования: постоянные магниты на основе систем Sm-Co и $\mathrm{Nd}-\mathrm{Fe}-\mathrm{B}$, никель-металлгидридные аккумуляторные батареи типа NiMH (где $\mathrm{M}$ - La, Nd и другие P3M) и фосфоры флуоресцентных (люминесцентных) ламп [1].

Структура потребления РЗМ является в целом достаточно стабильной, тем не менее в последние годы ожидаемо выросло использование РЗМ в выпуске магнитов до 23\%. Что касается отдельных P3М, то по данным работы [2], наиболее широко применяются церий (около 45 тыс. т), лантан (около 30 тыс. т), неодим (около 20 тыс. т) и иттрий (12 тыс. т). На долю этих металлов приходится $87 . .88 \%$ от мирового потребления РЗМ. Рассмотрение спроса на РЗМ в системе координат глобальной экономики позволяет выделить три основные сферы их использования, которые в ближайшие годы будут представлять собой характерные тренды развития: это «чистые» технологии (так называемая «зеленая энергетика»), товары повседневного использования («товары для жизни») и военно-промышленный комплекс (средства вооружения и обороны). Считается, что спрос на РЗМ в кратко- и долгосрочной перспективах будет поддерживаться развитием рынков, базирующихся на экологически чистых технологиях, таких как производство электромобилей и ветровых турбин. Согласно прогнозу в 2020 г. мировой объем потребления РЗМ увеличится до 180 тыс. т при уровне ежегодного роста $\sim 5,7 \%$. При этом объем потребления РЗМ Китаем к 2020 г. составит около 120 тыс. т, производство РЗМ вне Китая составит не более 65 тыс. т [2].

\section{ВТОРИЧНОЕ СЫРЬЕ РЗМ}

В связи с большим спросом на РЗМ и их высокой стоимостью в последнее время повышенное внимание уделяется использованию вторичного сырья для получения этих металлов. В первую очередь это такие РЗМ-содержащие отработанные изделия и материалы, как постоянные магниты, никель-металлгидридные аккумуляторные батареи, люминофоры, катализаторы. Проблеме извлечения РЗМ из различных видов вторичного сырья авторы настоящей статьи посвятили несколько работ [3-8]. В настоящем сообщении сделан обзор последних (2016-2017 гг.) работ по этой проблеме, не обсуждаемой в ранее опубликованных статьях.

Производственные циклы РЗМ-промышленности включают многочисленные фазы, каждая из которых характеризуется своей сложной рыночной динамикой: добычей руды; извлечением оксидов РЗМ, их очисткой; восстановлением оксидов до металлов, включением металлов и сплавов в компоненты и производством конечной продукции. Таким образом, развитие РЗМ-промышленности включает широкий круг вопросов: от добычи руд и использования вторичных источников сырья до получения чистых и особо чистых индивидуальных редкоземельных элементов и их применения в оборонных и гражданских отраслях.

В категорию вторичных сырьевых ресурсов РЗМ возвращается лишь $1 \%$ используемых РЗМ вследствие их сильного рассеяния и трудностей при сборе отходов. В связи с этим в работе [9] подчеркивается необходимость повышения эффективности технологий извлечения РЗМ из вторичного сырья.

При анализе реверсивной логистики и распределения ресурсов в РЗМ-промышленности в работе [10] была введена схема реверсивной логистической сети в соответствии с процедурой рециклирования РЗМ. Ключевой точкой в этой сети был выбор оборудования и проектирование реверсивного логистического уровня для уменьшения загрязнений и ущерба природной окружающей среде. Оптимальное использование Р3М должно повысить развитие реверсивной 
логистики в РЗМ-промышленности и поддержать преимущества утилизации РЗМ.

\section{ОТХОДЫ МАГНИТНЫХ СПЛАВОВ}

Создание нового класса постоянных магнитов из сплавов лантаноидов с кобальтом, железом и бором явилось выдающимся событием 60-х (1966 г.) и 80-х (1984 г.) годов XX столетия. Самарий-кобальтовые магниты (сплав $\mathrm{SmCo}_{5}$ ) превосходят другие распространенные магнитные материалы в 2-4 раза по величине магнитной энергии на единицу объема и в 5-10 раз по величине коэрцитивной силы. Еще большей магнитной энергией обладают сплавы на основе системы неодим-железо-бор (сплав $\mathrm{Nd}_{2} \mathrm{Fe}_{14} \mathrm{~B}$ ).

Вопросы совершенствования технологии

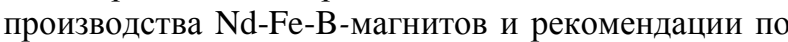
ее оптимизации рассмотрены в работе [11]. Там же рассмотрены вопросы рециклирования РЗМ при переработке отходов производства и потребления постоянных магнитов и снижения ее стоимости. Рекомендуется при переработке отходов осуществлять раздельный сбор легких РЗМ (неодим, празеодим) и тяжёлых (диспрозий, тербий).

Технология выплавки сплавов системы Р3M-FeСо-В для термически стабильных магнитов, обеспечивающая стабильность химического состава (отклонения по содержанию РЗМ $\pm 1,0$, кобальта и бора по $\pm 0,5$ мас.\% от расчетного и чистота по примесям: алюминий и никель < 0,2 мас.\% каждого, кислород $<0,1$ мас.\%), показана в работе [12]. Данная технология позволяет получать как сплавы системы Pr-Dy-Fe-Co-B, так и более сложные композиции, включающие дополнительные РЗМ, например, гадолиний.

На первых стадиях производства постоянных магнитов на основе сплава $\mathrm{Nd}-\mathrm{Fe}-\mathrm{B}$ часть порошкового материала попадает в отходы. В ходе исследований в [13] была установлена возможность использования способа магнитной сепарации для очистки порошковых отходов от фракций, загрязненных оксидом неодима выше допустимой нормы. Из очищенных этим способом порошков были изготовлены образцы постоянных магнитов, которые показали более высокие магнитные параметры (остаточную индукцию, коэрцитивную силу), чем полученные другими методами очистки.

В статье японских ученых [14], посвященной переработке скрапа постоянных магнитов состава $\mathrm{Nd}_{2} \mathrm{Fe}_{14} \mathrm{~B}$, содержащих добавки $\mathrm{Pr}$ и Dy, представлены последние достижения в технологиях извлечения РЗМ и их рационального использования. Япония все РЗМ экспортирует из Китая, поэтому их рециклирование является для нее крайне актуальной задачей. Рециклинг РЗМ из отходов осуществляется компаниями Hitachi, Mitsubishi Materials и Showa Denko KK.

Термодинамическое моделирование и экспериментальное изучение системы $\mathrm{B}_{2} \mathrm{O}_{3}-\mathrm{FeO}$ $\mathrm{Fe}_{2} \mathrm{O}_{3}-\mathrm{Nd}_{2} \mathrm{O}_{3}$ проведены в работе [15]. Термодинамические расчеты этой системы позволили оптимизировать селективный процесс окисления неодима при переработке отходов магнитов и тем самым повысить его извлечение.

Основной технологией переработки скрапа постоянных магнитов на основе системы $\mathrm{Nd}-\mathrm{Fe}-\mathrm{B}$ является гидрометаллургическая, которая предусматривает выщелачивание отходов. Так, в работе [16] показано, что при оптимальных режимах выщелачивания скрапа полностью извлекаются в раствор железо, бор, неодим и 85,87\% кобальта. При последующем электролизе раствора получали металлы высокой чистоты, в том числе и неодим.

В работе [17] скрап постоянных магнитов, содержащий $64,37 \mathrm{Fe} ; 30,57 \mathrm{Nd} ; 0,42 \mathrm{Pr}$ и $0,71 \% \mathrm{~B}$, выщелачивали раствором соляной кислоты. Оптимальный режим для максимального извлечения неодима $(99,9 \%)$ и железа $(61,36 \%)$ следующий: концентрация выщелачивателя $0,2 \mathrm{M} \mathrm{HCl}$, температура и длительность процесса $90^{\circ} \mathrm{C}$ и 4 ч соответственно, крупность материала 76...105 мкм, интенсивность перемешивания 800 об./мин, плотность пульпы $1 \%$. Из раствора осаждали железо добавкой $\mathrm{Ca}(\mathrm{OH})_{2}$ до $\mathrm{pH}=4,0$. После удаления железа проводили жидкостную экстракцию 0,8 $\mathrm{M} \mathrm{NaD}_{2}$ EHPA с последующей реэкстракцией и получением раствора, содержащего 72 г/л неодима и 1,088 г/л празеодима. В результате кристаллизации осаждали соли $\mathrm{Nd}_{2}\left(\mathrm{SO}_{4}\right)_{3}$ и $\mathrm{Pr}_{2}\left(\mathrm{SO}_{4}\right)_{3}$.

При переработке отходов производства постоянных магнитов для извлечения из растворов после выщелачивания диспрозия и неодима в [18] использовали два экстрагента: Д2ЭГФК и РС 88 А. В работе предложены оптимальные режимы экстракции и реэкстракции диспрозия и неодима для их промышленной регенерации.

Как показано в [19], экстракция неодима и празеодима из растворов хлоридов после выщелачивания скрапа магнитов $\mathrm{Nd}-\mathrm{Fe}-\mathrm{B}$ в бифункциональных ионных жидкостях $\mathrm{R}_{4} \mathrm{NCy}$ и $\mathrm{R}_{4} \mathrm{ND}$ идет более эффективно, чем в обычных экстрагентах. При оптимальных режимах извлечение неодима составило 98,79\% и празеодима 99,02\%. Реэкстракцию вели серной кислотой.

Зачастую перед выщелачиванием скрапа магнитов проводят окислительный обжиг. Так, в работе [20] разработан способ 95...100\%-го извлечения $\mathrm{Nd}, \mathrm{Pr}, \mathrm{Dy}$ и $\mathrm{Gd}$ с переводом железа в гематит и гетит. Вначале отходы подвергают низкотемпературному $\left(200{ }^{\circ} \mathrm{C}\right)$ обжигу, а затем проводят водное выщелачивание и очистку раствора от примесей. В работе [21] окислительный обжиг проводили перед соляно-кислотным выщелачиванием скрапа. При обжиге степень окисления железа до $\mathrm{Fe}^{3+}$ достигает максимума при $700{ }^{\circ} \mathrm{C}$ за 1,5 ч. Степень выщелачивания неодима составила $99,33 \%$ при $\mathrm{pH}=3,5$ за 2 ч, остаточное содержание железа в растворе - 0,00014 г/л.

Фторирование и электролиз составляют основу

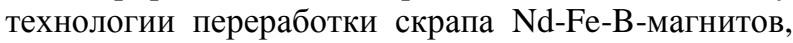
представленной в работе [22]. При фторировании отходов с использованием флюсов $\mathrm{AlF}_{3}, \mathrm{ZnF}_{2}, \mathrm{FeF}_{3}$ и $\mathrm{Na}_{3} \mathrm{AlF}_{6}$ неодим и диспрозий переходят в расплав на основе LiF в форме фторидов, в то время как железо 
и бор остаются в элементарном состоянии. При электролизе РЗМ растворяются на аноде и осаждаются на катоде.

Способ переработки шлифотходов, образующихся в процессе производства РЗМ-содержащих магнитов, предлагается в патенте [23]. Шлифотходы смешивают с концентрированной (не менее 92\%) серной кислотой в количестве, необходимом для получения твердого агломерированного продукта. Затем проводят процесс твердофазной сульфатизации при температуре $200 \ldots 250{ }^{\circ} \mathrm{C}$, после чего проводят обжиг при $650 \ldots 850^{\circ} \mathrm{C}$. Далее проводят выщелачивание в перколяционных колоннах сульфатов РЗМ и других металлов подкисленной водой и выделение РЗМ из продуктивных растворов осаждением. Твердый остаток выщелачивания (кек) представляет собой практически чистый оксид трехвалентного железа. При этом достигается 94...98\% извлечение суммы РЗМ в раствор при минимальном переходе железа и других примесей в раствор в виде сульфатов.

\section{ДРУГИЕ ВИДЫ ОТХОДОВ}

Никель-металлгидридные батареи, наряду с ионными литиевыми, относятся к новому классу перезаряжаемых аккумуляторных батарей. В использованных NiMH аккумуляторных батареях кроме никеля и кобальта содержатся $\mathrm{La}, \mathrm{Sm}, \mathrm{Nd}, \mathrm{Pr}$, $\mathrm{Ce}$, поэтому скрап таких батарей рассматривается как вторичное сырье РЗМ.

Оптимальный режим выщелачивания скрапа Ni-MН-батарей приведен в работе [24]: концентрация выщелачивателя $2 \mathrm{MH}_{2} \mathrm{SO}_{4}$, температура и продолжительность процесса 348 К и 120 мин соответственно, плотность пульпы 100 г/л . Извлечение РЗМ в раствор составило: 98,1 Nd; 98,4 Sm; 95,5 Pr; 89,4\% Се. При этом тяжелые металлы (Ni, Co, Mn, Zn) растворились более чем на $90 \%$.

Электродные материалы $\mathrm{AB}_{5}$-типа NiMHбатарей могут быть переплавлены для получения никель-кобальтового сплава и шлака, обогащенного РЗМ-оксидами. В работе [25] плавку вели при температуре $800 \ldots 900{ }^{\circ} \mathrm{C}$ с добавкой $\mathrm{H}_{2} / \mathrm{H}_{2} \mathrm{O}$. При этом РЗМ, алюминий и марганец окислялись, а более инертные - никель и кобальт, переходили в элементарное состояние. Второй переплав электродных материалов проводили при $1550{ }^{\circ} \mathrm{C}$ с добавлением флюсов $\mathrm{SiO}_{2}$ и $\mathrm{Al}_{2} \mathrm{O}_{3}$ и получали $\mathrm{Ni}-\mathrm{Co}-$ сплав и шлак состава $\mathrm{P} 3 \mathrm{M}-\mathrm{SiO}_{2}-\mathrm{Al}_{2} \mathrm{O}_{3}-\mathrm{MnO}$. Никелькобальтовый сплав может быть использован для получения $\mathrm{AB}_{5}$-сплава для хранения водорода, а из шлака, содержащего до 48,5\% РЗМ-оксидов, извлекают индивидуальные РЗМ.

Одним из видов вторичного сырья РЗМ являются отработанные катализаторы. Предложенная в патенте [26] многоступенчатая технологическая схема извлечения церия из отработанных железокалиевых катализаторов дегидрирования олефиновых углеводородов завершается кристаллизацией диоксида церия при выдержке раствора в течение $3 . .12$ ч при температурах до минус $20{ }^{\circ} \mathrm{C}$. Выделив- шийся осадок отделяют от маточного раствора декантацией и фильтрованием, промывают на фильтре от соединений железа и сушат до постоянной массы.

Для извлечения РЗМ из отходов катализаторов крекинга нефти может быть применено биовыщелачивание. В работе [27] для этой цели использовали штамм Gluconobacter oxydans, при этом извлечение РЗМ составляло всего 49\%, однако показано, что оно возрастает при выщелачивании с добавкой в раствор глюконовой кислоты в количестве до 90 ммоль/л.

Особенно возросла потребность в РЗМ в связи с бурным развитием электроники. В электронных приборах из РЗМ наиболее часто используется лантан. В работе [28] для извлечения лантана из скрапа электронных приборов его растворяли в кислоте и проводили сорбцию лантана обычной глиной или органоглиной (полиаминовой глиной). Было показано, что глины обладают катионообменным свойством, сорбируя на себе металлы (в данном случае лантан и медь).

Наиболее широко люминофоры используют в люминесцентных лампах - самых экономичных источниках света, в цветном и черно-белом телевидении, а также для изготовления светящихся красок (люминесцентные составы на основе иттрия, европия, тербия и других лантаноидов). Для переработки отходов люминофоров используют, в частности, технологию хлорирования. В патенте [29] предложен способ получения обогащенного по иттрию и европию концентрата при переработке отходов люминофоров на основе сульфида цинка. Способ включает сушку сырья при температуре $150 \ldots 320^{\circ} \mathrm{C}$ в течение $2 \ldots 3$ ч и последующее хлорирование при $800 \ldots 900{ }^{\circ} \mathrm{C}$ в расплаве хлористых солей иттрия и европия при массовом соотношении хлорида иттрия к хлориду европия $1:(0,1 \ldots 0,3)$.

Получение индивидуальных оксидов РЗМ (иттрия и европия) из отходов люминофоров методами хлорирования сырья на стадии его вскрытия и экстракции олеиновой кислотой на стадии разделения иттрия и европия рассмотрено в работе [30]. Исследования процесса экстракции, выполненные на модельных растворах, подтверждены испытаниями на технологических растворах, содержащих 125 г/л суммы лантаноидов (96\% иттрия и 4\% европия) и до 10 г/л цинка. Чистота полученных оксидов составила: 99,91\% европия и 99,90\% иттрия. Экспериментально было показано, что олеиновая кислота обладает рядом преимуществ по сравнению с другими экстрагентами. Помимо высоких значений коэффициентов разделения пары европий/иттрий (не ниже 4,0), она характеризуется значительной емкостью (от 12 до 26 г/л суммы иттрия и европия в пересчете на оксиды - в зависимости от концентрации экстрагента в разбавителе) и низкой стоимостью.

Предварительная обработка отходов флуоресцентного порошка может повлиять на степень извлечения их него РЗМ при последующем выщелачивании. Так, в работе [31] показано, что выдержка 
порошка в течение 2 ч при температуре $1050{ }^{\circ} \mathrm{C}$ в

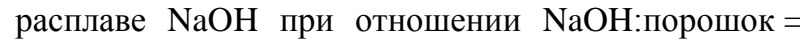
$=2,5: 1$ позволяет повысить извлечение РЗМ более чем до $98 \%$.

Скрап флуоресцентных ламп может служить вторичным сырьем для извлечения $\mathrm{Eu}, \mathrm{Y}, \mathrm{Ce}, \mathrm{Tb}$, Gd, La. Иx среднее содержание в скрапе оценивается в 8,4 г/кг, а содержание ртути составляет $(0,7 \pm 0,1)$ г/кг. При переработке скрапа флуоресцентных ламп в промышленном масштабе применяют технологию экстракции. Реагент Cуanex 572, растворенный в керосине, использовали для жидкостной экстракции иттрия и европия с получением оксидов чистотой $99,82 \% \mathrm{Y}_{2} \mathrm{O}_{3}$ и $91,6 \%$ $\mathrm{Eu}_{2} \mathrm{O}_{3}$ [32]. Оптимальным режимом для разделения Р3М установлен $\mathrm{pH}=0$ для выделения иттрия с последующим выделением европия при $\mathrm{pH}=1$. Повышение температуры с 25 до $65^{\circ} \mathrm{C}$ приводило к ухудшению разделения металлов. Реэкстракцию вели соляной кислотой.

Извлечение РЗМ из фосфорных ламповых отходов посредством восстановительной щелочной плавки с последующим кислотным выщелачиванием рассмотрено в работе [33]. В качестве восстановителя применяли железный порошок, соотношение щелочи к массе фосфора составляло 2:1, температура $-700{ }^{\circ} \mathrm{C}$, длительность -3 ч. Выщелачивание вели соляной кислотой концентрации 3 моль/л при Ж:Т = 7,5:1, температуре $70{ }^{\circ} \mathrm{C}$ в течение 1 ч. Общее извлечение РЗМ достигало 99,35\%, а для церия, европия, тербия и иттрия соответственно - 98,12; 99,93; 99,97 и 99,60\%.

В заключение укажем, что предложенные технологии пока не получили должного экономического обоснования. Большинству из них присущи факторы, сдерживающие их внедрение, среди которых не только экономические обоснования, но и экологические.

\section{БИБЛИОГРАФИЧЕСКИЙ СПИСОК}

1. Е.Г. Поляков, А.С. Сибилев. Извлечение РЗЭ из техногенного сырья // Цветная металлургия. 2015, №2, c. 66-67.

2. С.А. Черный, А.И. Петрова. Перспективы развития рециклинга РЗМ в мире // Актуальные вопросы получения и применения РЗМ - 2015: Матер. Междунар. науч.-практ. конф., Москва, 25 июня 2015. М., 2015, с. 68-71.

3. Г.А. Колобов, В.В. Павлов, Ю.В. Мосейко. Извлечение редкоземельных и радиоактивных металлов из вторичного сырья // Теория и практика металлургии. 2013, №5-6, с. 110-115.

4. G.A. Kolobov, V.V. Pavlov, T.N. Nesterenko, Yu.V. Mosejko. Extraction of rare-earth metals from secondary raw materials // Nauka i Studia (Polska). 2013, N42(110), p. 70-74.

5. G.A. Kolobov, T.V. Kritskaya, V.Y. Yvanov, et al. Featyres of production of high purity rare earth metals for electronics // Central Asian Material Science Journal. 2016, N5, p. 31-38.

6. Г.А. Колобов, Н.Н. Ракова, Ю.В. Мосейко и др. Извлечение редкоземельных металлов из отходов магнитных сплавов и изделий из них. Сообщение 1. Отходы сплавов системы самарийкобальт и отработанные аккумуляторные батареи // Металургія: наукові праці ЗДІА. 2016, в. 2(36), с. 3642.

7. Г.А. Колобов, В.К. Лисица, Ю.В. Мосейко и др. Извлечение редкоземельных металлов из отходов магнитных сплавов и изделий из них. Сообщение 2. Отходы сплавов системы неодимжелезо-бор // Металургія: наукові пращі ЗДІА. 2017, B. 1(37), c. $34-40$.

8. Г.А. Колобов, В.В. Павлов, Ю.В. Мосейко и др. Извлечение редкоземельных металлов из вторичного и техногенного сырья // Металургія: наукові праці ЗДІА. 2017, в. 2(38), с. 38-45.

9. Li Hongxu, Wang Shuai, Li Chao. Recycling and life cycle analysis of rare earth elements // Chin. J. Rare Metals. 2016, v. 40, N 9, p. 945-954.

10. Xu Ligang. Construction scheme, function and elements of the revers logistics network in rare earth industry // Nonferrous Met. Sci. and Eng. 2015, v. 6, N 4, p. 121-124.

11. K. Machida. Recent progress production and recycling processes for Nd-Fe-B magnetes // Magn. Jap. 2016, v. 11, N 1, p. 14-20.

12. П.Г. Мин, В.Е. Вадеев, А.Г. Евгенов, В.П. Пискорский. Разработка технологий выплавки сплавов системы PЗM-Fe-Co-B для термически стабильных магнитов // Металль. 2015, №6, с. 3743.

13. Д.А. Кутепов, Н.Н. Давыдов. Исследование возможности и режимов магнитной сепарации отходов производства постоянных магнитов на основе сплава $\mathrm{Nd}-\mathrm{Fe}-\mathrm{B}$ для их повторного использования в производстве постоянных магнитов // Наука и образование: проблемы и тенденциии развития: Матер. 3 Междунар. науч.-практ. конф. Уфа, 2015, с. 87-94.

14. H. Sekimoto, K. Yamaguchi. Recent progress with techniques for recovering rare earth elements from neodymium magnet // Magn. Jap. 2016, v. 11, N 1, p. 21-26.

15. L.K. Jakobsson, G. Tranell, I. Jung. Experimental investigation and thermodynamic modeling of the $\mathrm{B}_{2} \mathrm{O}_{3}-\mathrm{FeO}-\mathrm{Fe}_{2} \mathrm{O}_{3}-\mathrm{Nd}_{2} \mathrm{O}_{3}$ system for recycling of $\mathrm{NdFeB}$ magnet scrap // Met. And Mater. Trans. B. 2017, v. 48, N 1, p. 60-72.

16. C. Lee, H. Yen, C. Liao, et al. Hydrometallurgical processing of $\mathrm{Nd}-\mathrm{Fe}-\mathrm{B}$ magnets for $\mathrm{Nd}$ purification // J. Mater. Cycl. and Waste Manag. 2017, v. 19, N 1, p. 102-110.

17. P.K. Parthi, T.R. Sethy, P.C. Rout, K. Sarangi. Separation and recovery of neodynium and praseodymiym from permanent magnet scrap through the hydrometallurgical route // Separ. Sci. and Technol. 2016, v. 51, N 13, p. 2232-2241.

18. H. Yoon, C. Kim, K. Chung, et al. Solvent extraction and recovery of dysprosium (Dy) and neodymium (Nd) from aqueous solutions: Waste recycling strategies for permanent magnet processing // Hydrometallurgy. 2016, v. 165, p. 27-43. 
19. E. Padhan, K. Sarangi. Recovery of Nd and Pr from $\mathrm{NdFeB}$ magnet leachates with bi-functional ionic liquids based on Aliquat 336 and Cyanex 272 // Hydrometallurgy. 2017, v. 167, p. 134-140.

20. Onal Mehmet Ali Recai, E. Aktan, C. Borra, et al. Recycling of $\mathrm{NdFeB}$ magnets using nilration, calcinations and water leaching for REE recovery // Hydrometallurgy. 2017, v. 167, p. 115-123.

21. J. Wu, G. Deng, L. Dang, C. Lin, et al. Rare earth recovery from $\mathrm{Nd}-\mathrm{Fe}-\mathrm{B}$ magnet scrap // Nonferrous Met. Sci. and End. 2016, v. 7, N 1, p. 119 124.

22. A. Abbasalizadeh, An. Malflet, S. Seetharaman, et al. Electrochemical recovery of rare earth elements from magnets: conversion of rare earth based metals into rare earth fluorides in molten salts // Mater. Trans. 2017, v. 58, N 3, p. 400-405.

23. Пат. 2574543 Рос. Федерация, МПК С 22 В 59/00 (2006.01), С 22 В 7/00 (2006.01), С 22 В 3/08 (2006.01). Способ переработки илифотходов от производства постоянных магнитов /ВНИИХТ, А.В. Калашников, Е.В. Щукина, И.В. Кузнецов, Ю.М. Трубаков. Заявитель и патентообладатель ВНИИХТ. №2014146056/02. Заявл. 17.11.2014, опубл. 10.02.2016.

24. P. Meshram, P.D. Pandey, T.R. Mankhand. Process optimization and kinetics for leaching of rare earth metals from the spent the Ni-metal hydride batteries // Waste Manag. 2016, v. 51, p. 196-203.

25. Y. Jiang, Y. Deng, W. Bu. Pyrometallurgical Extraction of Valuable Elements in Ni-Metal Hydride Battery Electrode Materials // Met. and Mater. Trans. 2015, v. 46, N 5, p. 2153-2157.

26. Пат. 2618024 Рос. Федерация, МПК С 22 В 59/00 (2006.01), C 01 F 17/00 (2006.01), В 01 J 23/10 (2006.01). Способ извлечения иерия / А.А. Ламберов, А.Ш. Бикмурзин, Р.Г. Романова. №2015150364. Заявл. 24.11.2015, опубл. 02.05.2017.
27. D.W. Reed, Y. Fujita, D.L. Daubaras, et al. Bioleaching of rare earth elements from waste phosphors and cracking catalysts // Hydrometallurgy. 2016, v. 166, p. 34-40.

28. E.M. Iannicelli-Zubiani, C. Cristiani, G. Dotelli, S.P. Gallo. Recovery of valuable metals from electronic scraps by clays and organo-clays: Study on bi-ionic model solutions // Waste Manag. 2017, v. 60, p. $582-590$.

29. Пат. 2595314 Рос. Федерация, МПК С 22 В 59/00 (2006.01), С 22 В 7/00 (2006.01), С 22 В 1/08 (2006.01). Способ переработки отходов люминофоров на основе сульфида цинка, содержащих иттрий и европий / ГИРЕДМЕТ, Н.В. Туляков, А.А. Гасанов, О.В. Юрасова, М.П. Блитман. Заявитель и патентообладатель ГИРЕДМЕТ. №2015111998/02. Заявл. 02.04.2015, опубл. 27.08.2016.

30. С.А. Василенко, О.В. Юрасова, Т.В. Добрынина, А.Б. Арзманова. Получение индивидуальных оксидов редкоземельных металлов из отходов люминофоров // Цветные металльл. 2017, №9, с. 6368.

31. Z. Zhang, R. Wang, J. Xiong, et al. Effect of alkaline fusion pretreatment on extraction rate of rare earth from waste rare earth fluorescent powder // Nonferrous Met. Sci. and Eng. 2016, v. 7, N 6, p. 129135.

32. C. Tunsu, J.B. Lapp, C. Ekberg, T. Retegan. Selective separation of yttrium and europium using Cyanex 572 for applications in fluorescent lamp waste processing // Hydrometallurgy. 2016, v. 166, p. 98-106.

33. Y. Liang, Y. Liu, R. Lin, et al. Leaching of rare earth elements from waste lamp phosphormoxtures dy reduced alkali fusion followed by acid leaching // Hydrometallurgy. 2016, v. 163, p. 99-103.

\section{ВИЛУЧЕННЯ РІДКОЗЕМЕЛЬНИХ МЕТАЛІВ ІЗ ВТОРИННОЇ СИРОВИНИ}

\section{Г.О. Колобов, В.В. Павлов, К.А. Печериця, Ю.В. Мосейко, Н.В. Лічконенко, А.Д. Прохорова}

Дано огляд нових публікацій, що присвячені технологіям вилучення рідкоземельних металів (РЗМ) із різноманітних видів вторинної сировини: скрапу постійних магнітів, виготовлених із сплаву $\mathrm{Nd}_{2} \mathrm{Fe}_{14} \mathrm{~B}$, $\mathrm{i}$ нікель-металгідридних акумуляторних батарей; відпрацьованих каталізаторів; скрапу електроніки; відходів люмінофорів і скрапу флуоресцентних ламп.

\section{EXTRACTING OF RARE EARTH METALS FROM SECONDARY RAW MATERIALS}

\section{G.A. Kolobov, V.V. Pavlov, K.A. Pecherytsya, Yu.V. Moseiko, N.V. Lichkonenko, A.D. Prochorova}

A review of new publications on rare earth extraction technologies from various types of secondary raw materials: permanent magnet scrap made of $\mathrm{Nd}_{2} \mathrm{Fe}_{14} \mathrm{~B}$ alloy and nickel-metal hydride batteries, spent catalysts, electronics scrap, waste luminophores and scrap fluorescent lamps. 